\title{
A Direct Dynamics Study of Protonated Alcohol Dehydration and the Diels-Alder Reaction
}

\author{
Marcus V. P. dos Santos, Erico S. Teixeira and Ricardo L. Longo* \\ Departamento de Química Fundamental, Universidade Federal de Pernambuco, 50740-540 Recife-PE, Brazil
}

\begin{abstract}
As dinâmicas da desidratação do álcool protonado $(R)$-3,3-dimetilbutan-2-ol (álcool pinacolil), $\left[\left(\mathrm{CH}_{3}\right)_{3} \mathrm{C}-\mathrm{CH}\left(\mathrm{OH}_{2}\right) \mathrm{CH}_{3}\right]^{+}$, e da cicloadição eteno + 1,3-butadieno foram estudadas com a técnica de dinâmica molecular direta de Born-Oppenheimer (BOMD) usando o método AM1. Mais de 10.000 trajetórias foram geradas, em que a maioria foi utilizada no procedimento ainda não explorado de recozimento simulado/fragmentação (SA/F). A energia potencial obtida com o método AM1 (PES-AM1) para o álcool protonado apresenta dois estados de transição associados ao intermediário complexo $\left[\left(\mathrm{CH}_{3}\right)_{3} \mathrm{C}-\mathrm{CHCH}_{3}\right]^{+} \ldots \mathrm{OH}_{2}$ e a migração do grupo $\mathrm{CH}_{3}$ levando ao produto complexo $\left[\left(\mathrm{CH}_{3}\right)_{2} \mathrm{C}-\mathrm{CH}\left(\mathrm{CH}_{3}\right)_{2}\right]^{+} \cdots \mathrm{OH}_{2}$. A dinâmica direta forneceu um número desprezível de trajetórias envolvendo estes complexos, pois o momento adquirido pelo fragmento $\mathrm{H}_{2} \mathrm{O}$ leva à dissociação completa. Portanto, o rearranjo do carbocátion secundário $\left[\left(\mathrm{CH}_{3}\right)_{3} \mathrm{C}-\mathrm{CHCH}_{3}\right]^{+}$foi praticamente inexistente durante a dinâmica. Apesar do caminho concertado (dissociação do fragmento $\mathrm{H}_{2} \mathrm{O}$ e migração do grupo $\mathrm{CH}_{3}$ ) não ser uma coordenada de reação intrínseca (IRC) no método PESAM1, um número significativo de trajetórias envolveu este caminho. Para a reação de Diels-Alder, mesmo partindo-se do estado de transição simétrico, e utilizando uma função de onda AM1 restrita, a dinâmica forneceu um número significativo de trajetórias que seguiram caminhos assimétricos, isto é, não-IRC, em direção ao ciclohexeno, independentemente do procedimento utilizado na inicialização. E notável ainda que todas estas trajetórias que seguiram caminhos assimétricos envolveram um caminho de reação concertado.
\end{abstract}

The dynamics of dehydration of the protonated (R)-3,3-dimethylbutan-2-ol (pinacolyl alcohol), $\left[\left(\mathrm{CH}_{3}\right)_{3} \mathrm{C}-\mathrm{CH}\left(\mathrm{OH}_{2}\right) \mathrm{CH}_{3}\right]^{+}$, and of ethene + 1,3-butadiene cycloaddition were studied with the BornOppenheimer molecular dynamics (BOMD) technique for direct dynamics using the AM1 method. More than 10,000 trajectories were generated, most of them related to the unexplored simulated annealing/fragmentation approach. The AM1 potential energy surface (PES) for the protonated pinacolyl alcohol presents two transition states related to the $\left[\left(\mathrm{CH}_{3}\right)_{3} \mathrm{C}-\mathrm{CHCH}_{3}\right]^{+} \ldots \mathrm{OH}_{2}$ intermediate complex and to $\mathrm{CH}_{3}$ migration leading to the $\left[\left(\mathrm{CH}_{3}\right)_{2} \mathrm{C}-\mathrm{CH}\left(\mathrm{CH}_{3}\right)_{2}\right]^{+} \ldots \mathrm{OH}_{2}$ product complex. Direct dynamics yielded negligible trajectories involving these complexes, since the momentum acquired by the $\mathrm{H}_{2} \mathrm{O}$ fragment led to a complete dissociation. Thus, rearrangement of the secondary carbocation $\left[\left(\mathrm{CH}_{3}\right)_{3} \mathrm{C}-\mathrm{CHCH}_{3}\right]^{+}$was practically inexistent during the dynamics. Despite the concerted path $\left(\mathrm{H}_{2} \mathrm{O}\right.$ dissociation and $\mathrm{CH}_{3}$ migration) not being an IRC (intrinsic reaction coordinate) path in AM1-PES, a statistically significant number of trajectories involved this path. As for the Diels-Alder reaction, even when started from a symmetric transition state using the spin restricted AM1 wavefunction, the dynamics yielded a significant number of trajectories that followed asymmetric, i.e. non-IRC, paths toward cyclohexene, independent of the initialization approach. It is noteworthy that all these asymmetric path trajectories led to a concerted reaction mechanism.

Keywords: protonated pinacolyl, ethene + 1,3-butadiene, cycloaddition, non-IRC

\section{Introduction}

Recently, time-dependent methods, ${ }^{1,2}$ particularly direct dynamics classical trajectory ones, ${ }^{3,4}$ have been more routinely used to study the dynamical aspects of chemical reactions. ${ }^{5-12}$ As a result, several limitations of methods

*e-mail: longo@ufpe.br based upon a static analysis of the potential energy surface (PES), such as the intrinsic reaction coordinate (IRC), ${ }^{13}$ or upon restricted regions of the PES, such as transition state theory (TST), have been uncovered. ${ }^{5-12}$ For example, the use of TST is insufficient to describe the selectivity of deazetization of 2,3-diazabicyclo[2.2.1]hept-2-eneexo,exo-5,6- $d 2$, which might be explained by the dynamical 
behavior of the $\mathrm{CH}_{2}$ group as it recoils from the expelled $\mathrm{N}_{2}{ }^{14,15}$ Also, the formation of the $\mathrm{CH}_{3} \mathrm{OH} \cdots \mathrm{F}^{-}$hydrogenbonded complex in the $\mathrm{OH}^{-}+\mathrm{CH}_{3} \mathrm{~F} \rightarrow \mathrm{CH}_{3} \mathrm{OH}+\mathrm{F}^{-} \mathrm{S}_{\mathrm{N}} 2$ reaction is avoided in $90 \%$ of the calculated trajectories, despite the complex being $c a .125 \mathrm{~kJ} \mathrm{~mol}^{-1}$ more stable than the dissociated product $\mathrm{CH}_{3} \mathrm{OH}+\mathrm{F}^{-} .{ }^{12}$ Several other examples are related to borderline reactions ${ }^{16}$ that are characterized by the convergence of two or more related mechanisms which leads to another combining features of each one. However, the weights of each contributing mechanism to the combined one is quite difficult to predict by static or indirect approaches, since it might happen that the reaction proceed through a single TS to two or more different products. The reaction between ketyl radical anions and alkyl halides is an extensively studied example, ,-9,11,17-20 $^{-1}$ where, for the reaction $\mathrm{CH}_{2} \mathrm{O}^{--}+\mathrm{CH}_{3} \mathrm{Cl}$, three products, resulting from electron transfer (ET), substitution at carbon $(\operatorname{Sub}(\mathrm{C}))$ and substitution at oxygen $(\mathrm{Sub}(\mathrm{O}))$, can be formed, but the ET and $\operatorname{Sub}(\mathrm{C})$ involve the same tightly bound transition state. From $c a .200$ trajectories calculated at each of four different temperatures, the selectivity given by the ratio of ET to $\operatorname{Sub}(\mathrm{C})$ products varied from 1.02 to 1.43 at 148 to $598 \mathrm{~K}^{8}{ }^{8}$ Beyond the Born-Oppenheimer approximation, it has been shown that the coupling between the electrons and the nuclei with electron-nuclear dynamics (END) formalism ${ }^{2,21}$ is fundamental to obtain a qualitative and quantitative description of the electron transfer in the reaction $\mathrm{H}^{+}+\mathrm{H} \rightarrow \mathrm{H}+\mathrm{H}^{+} .22$ Thus, it might be expected that the inclusion of the electron-nuclear coupling would affect the ET:Sub(C) selectivity. A final example is the dehydration of protonated pinacolyl alcohol, $(R)-3,3-$ dimethylbutan-2-ol or $(R)-\left[\left(\mathrm{CH}_{3}\right)_{3} \mathrm{C}-\mathrm{CH}\left(\mathrm{OH}_{2}\right) \mathrm{CH}_{3}\right]^{+}$, where a TST or IRC analysis predicts a concerted path for the water dissociation and $\mathrm{CH}_{3}$ migration leading to the tertiary cation product $\left[\left(\mathrm{CH}_{3}\right)_{2} \mathrm{C}-\mathrm{CH}\left(\mathrm{CH}_{3}\right)_{2}\right]^{+},{ }^{10}$ while a direct $a b$ initio molecular dynamics trajectory calculations yield a reaction path through a secondary cation intermediate, $\left[\left(\mathrm{CH}_{3}\right)_{3} \mathrm{C}-\mathrm{CHCH}_{3}\right]^{+}$, and a negligible concerted reaction path. ${ }^{10}$

Classical trajectory methods require the specification of the initial conditions for the nuclei (positions and momenta) and, in some treatments, for the electrons. The outcome of a given trajectory is thus dependent upon these initial conditions and an ensemble of initial conditions has to be sampled in order to yield statistically relevant results or to compare with experimental data. This imposes severe computational demand upon the classical trajectory direct dynamics methods since at least hundreds of trajectories with different initial conditions have to be obtained. In addition, a classical description of the nuclear or atomic motions fails to account for some important quantum effects such as tunneling, crossings, interferences and, mainly, zero-point energy (ZPE). ${ }^{23,24}$ This last failure is significant since in quantum mechanics each oscillator mode is required to keep at least the ZPE associated with this mode. On the other hand, in a classical description, the modes can exchange energy without this ZPE restriction. There is still no consensus for the need to initially include ZPE to mimic the quantum nature of the initial state, however, it is clear that the unrestricted flow of energy during a classical trajectory can cause some unphysical behavior to appear. It is also common in classical molecular dynamics to distribute the initial energy, usually obtained from the classical equipartition energy ( $1 / 2 \mathrm{RT}$ for each appropriate degree of freedom), as random velocities for the nuclei consistent with a Maxwell-Boltzmann distribution at a temperature T. As a result, the initial energy will not be distributed along the normal modes, so that the trajectories would be quite different from those obtained by distributing this energy along the normal modes. Thus, one of the goals of the present contribution is to study the effects of distributing the classical equipartition energy to the nuclei using the random velocities approach and randomly through the normal modes. Also, a simulated annealing type approach ${ }^{25}$ has been employed to randomly perturb the system during its dynamical trajectory. This perturbation can partially mimic the collisions of the reactive system with other molecules or with the container walls.

The systems investigated here are $(i)$ dehydration of protonated pinacolyl alcohol, $(R)$-3,3-dimethylbutan-2-ol or $(R)-\left[\left(\mathrm{CH}_{3}\right)_{3} \mathrm{C}-\mathrm{CH}\left(\mathrm{OH}_{2}\right) \mathrm{CH}_{3}\right]^{+}$, and (ii) cycloaddition of ethene and 1,3-butadiene. As mentioned before, the first system has been studied by a direct $a b$ initio HF/6$31 \mathrm{G}^{*}$ molecular dynamics method, which yielded a reaction path involving a secondary cation intermediate, despite this species not being present in the HF/6-31G* PES and the only TS present is related to the concerted reaction path. We have chosen to study this system, since the PES using the AM1 method is quite different, as it presents two TS related to $\mathrm{H}_{2} \mathrm{O}$ dissociation to yield the $\left[\left(\mathrm{CH}_{3}\right)_{3} \mathrm{C}-\mathrm{CHCH}_{3}\right]^{+} \ldots \mathrm{OH}_{2}$ intermediate complex and to $\mathrm{CH}_{3}$ migration, connecting this intermediate and the rearranged $\left[\left(\mathrm{CH}_{3}\right)_{2} \mathrm{C}-\mathrm{CH}\left(\mathrm{CH}_{3}\right)_{2}\right]^{+} \ldots \mathrm{OH}_{2}$ product complex. A TS related to the concerted path has not been found. Considering these differences in the PES a rather distinct dynamical behavior would be expected when the AM1 method is employed. In addition, AM1-PES presents an intermediate and a product that are cation-dipole and hydrogen-bonded stable complexes, which in a dynamical treatment might not be present. ${ }^{12}$ The dynamical behavior of the Diels-Alder reaction has not been probed before by direct dynamics methods. In addition, the concertedness ${ }^{26,27}$ 
and synchronicity of this reaction has been a source of debate. ${ }^{28-36}$ Given the small energy difference between the concerted and nonconcerted reaction paths with AM1-PES, it might be expected that the inclusion of the dynamical effects in the description of this reaction mechanism is quite significant. Also, to our knowledge, this is the first time that the simulated annealing/fragmentation type approach has been used in the direct dynamics of reactive systems so that a detailed analysis of this approach is included.

\section{Theoretical calculations and computational procedures}

All electronic structure and Born-Oppenheimer molecular dynamics (BOMD) calculations were performed with the Gaussian 03 program. ${ }^{37}$ For the electronic structure calculations the default criteria for convergences were employed. The molecular dynamics simulations used $\mathrm{AM} 1^{38}$ classical trajectory calculations on the BornOppenheimer surface with a Hessian-based predictorcorrector algorithm. ${ }^{39,40}$ The predictor step employed a quadratic potential model to integrate to the end of the thrust radius with the Bulirsh-Stoer algorithm, where the energy, gradients, and Hessian were computed again. The values of the energy, gradients, and Hessian at the beginning and at the end of the predictor step were used to interpolate a fifth-order polynomial between these two points in the corrector step..$^{39}$ The predictor integration step was performed in normal coordinates, which does not strictly conserve angular momentum; ${ }^{40}$ however, considering that we are not interested in the state resolved dynamics of the products, this lack of exact conservation should not affect our conclusions.

The trajectories were started at the AM1 equilibrium geometry for protonated pinacolyl alcohol and at the AM1 transition state for the cycloaddition of ethene and 1,3-butadiene. The initial total kinetic energies of $105 \mathrm{~kJ} \mathrm{~mol}^{-1}\left(=0.040 \mathrm{E}_{\mathrm{h}}\right)$ and $75 \mathrm{~kJ} \mathrm{~mol}^{-1}\left(=0.0286 \mathrm{E}_{\mathrm{h}}\right)$ for the protonated pinacolyl alcohol and the Diels-Alder transition state, respectively, were consistent with a thermal distribution at $400 \mathrm{~K}$. Three procedures were used to distribute this energy, namely, (i) the initial atomic velocities were assigned from a random MaxwellBoltzmann distribution consistent with the simulation temperature (random velocities initialization); (ii) the initial kinetic energy was distributed randomly to the 10 lowest frequencies normal modes (random modes initialization); and (iii) random velocities initialization followed by a simulated annealing/fragmentation procedure (SA/F approach). It should be noted that for the first two approaches the total energy, and not the temperature, is conserved during the simulation.
Approaches i) and iii) should be contrasted with the random velocities initialization that adopts a velocity re-scaling algorithm in order to maintain the temperature constant during the trajectory calculation. ${ }^{20}$ It should also be noted that these approaches differ from others that take into account rotational energies sampled from a thermal distribution of a symmetric top..$^{41}$ Since this is one of the first explorations of the SA/F approach, some comments are in order. Once the dynamics is initialized by assigning random atomic velocities, it is perturbed by adding or subtracting an amount of energy from each normal mode either randomly or by a weighting function according to its frequency or a combination of both. The weighting function, w, for the $i$-th mode, is given by

$w(i)=\sqrt{\frac{1}{1+e^{-\beta\left[E_{\mathrm{F}}-\omega(i)\right]}}}$

where $\beta$ is the Fermi-Dirac inverse temperature $\left(E_{h}^{-1}\right), E_{F}$ is the Fermi energy $\left(\mathrm{cm}^{-1}\right)$ and $\omega$ is the frequency $\left(\mathrm{cm}^{-1}\right)$ of the vibrational mode. With this weighting function, all modes with frequencies smaller than $E_{F}$ will be enhanced and all above will be reduced if $\beta>0$; for $\beta<0$ the reverse will happen. In addition to the these three parameters, the $\mathrm{SA} / \mathrm{F}$ approach depends on the desired initial kinetic energy, which, in our case, is given by $1 / 2 \mathrm{RT}$ for each degree of freedom, excluded the center of mass motion, the amount of energy loss/gain (DelE) and the size of the random perturbation (DPert).

The trajectories were integrated to at least 2,000 steps (some up to 14,000 steps) for the protonated pinacolyl alcohol system and to at least 300 steps for the dynamics of the cycloaddition transition state, with a step size of $0.25 \mathrm{amu}^{1 / 2} a_{0}$, which ensured that the total energy and angular momentum was conserved to at least $10^{-6} \mathrm{E}_{\mathrm{h}}$ and $10^{-9} \hbar$, respectively, except for simulated annealing/ fragmentation trajectories. Some of them were integrated for longer times to minimize the chances of remaining trapped into local regions of the PES. For the dehydration reaction the numbers of trajectories generated were 100 for the random velocities initialization, 619 for the random modes initialization and 4,500 for the SA/F approach. For the Diels-Alder reaction, 100 trajectories were calculated for the random velocities initialization and for the random modes initialization, and 4,500 for the SA/F approach. The large number of SA/F trajectories are due to the combinations of its parameters, namely, $\beta$ $=0.001,0.005,0.010,0.050$, and $0.100 E_{\mathrm{h}}^{-1}, \mathrm{E}_{\mathrm{F}}=300$, 500, 750, 1000, 1250, 1500, 1750, 2000, 2250, 2500, 2750 , and $3000 \mathrm{~cm}^{-1}$, DPert $=0.001,0.005,0.010,0.050$, and $0.100 \mathrm{E}_{\mathrm{h}}$, and DelE $=0.001,0.005,0.010,0.050$, and $0.100 \mathrm{E}_{\mathrm{h}}$. The tree-flow chart for the $\mathrm{SA} / \mathrm{F}$ trajectories is 
presented in Figure S-I (Supplementary Information). For each set of parameters we used the options to add/remove energy from the normal randomly, weighted by w(i), or a combination of both.

For the protonated pinacolyl alcohol dynamics, Figure 1 illustrates the partitioning of the PES used for classification of the trajectories into reactant, intermediate and, product. Trajectories that went through the TS region are concerted paths, and those that did not go through TS1 or TS2 are labeled others. Two examples are presented in Figure 1. For the dynamics of the TS for the ethene and 1,3-butadiene cycloaddition, the trajectories were classified according to their degree of asymmetry, namely, for each trajectory towards the product, the differences between the distances of the two forming bonds are considered as the (non-) concertedness of the trajectory.

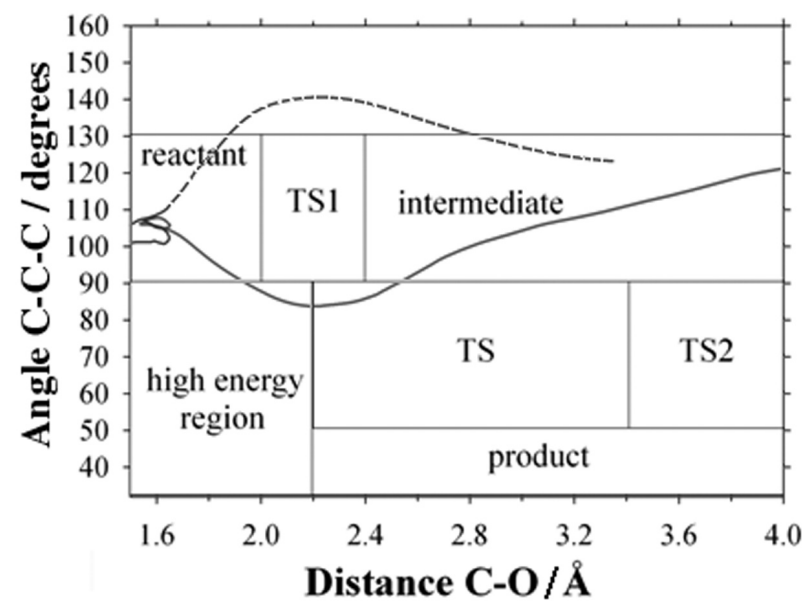

Figure 1. Partitioning of the potential energy surface (PES) for classification of the trajectories for protonated $(R)$-3,3-dimethylbutan-2ol, $\left[\left(\mathrm{CH}_{3}\right)_{3} \mathrm{C}-\mathrm{CH}\left(\mathrm{OH}_{2}\right) \mathrm{CH}_{3}\right]^{+}$. The two trajectories shown are examples of trajectories classified as others. C-O and C-C-C refer to the $\mathrm{C}(2)-\mathrm{O}$ distance and $\mathrm{C}(2)-\mathrm{C}(3)-\mathrm{C}(4)$ bond angle, with $\mathrm{C}(4)$ being the carbon atom anti to the $\mathrm{H}_{2} \mathrm{O}$ leaving group.

\section{Results and Discussion}

The results and their discussion are presented separately for the protonated $R-\left[\left(\mathrm{CH}_{3}\right)_{3} \mathrm{C}-\mathrm{CH}\left(\mathrm{OH}_{2}\right) \mathrm{CH}_{3}\right]^{+}$ pinacolyl alcohol and for the cycloaddition of ethene and 1,3-butadiene. For both systems, the PES are initially presented in order to provide descriptions based upon IRC. Then the dynamical aspects of each system are presented and compared to the IRC descriptions. These two systems have been chosen because they are prototypes for direct dynamics studies that start from the reactant(s) equilibrium structure(s) or from the transition state structure. Thus, the effects of the initial conditions as well as the perturbations on the trajectories can be analyzed for these two limiting cases.
Before presenting the results some comments on the choice of the electronic structure method is in order. We have chosen the AM1 method for the electronic structure calculations since we performed more than 10,000 trajectories with at least 2,000 time steps, so that higher level electronic structure methods ( $a$ b initio or DFT) were prohibitive. Also, we have not used newer semiempirical methods such as $\mathrm{RM} 1^{42}$ or $\mathrm{PM} 6^{43}$ since these methods have not been fully implemented and/or tested for dynamical calculations within the Gaussian 03 program.

Protonated 3,3-dimethylbutan-2-ol, [ $\left(\mathrm{CH}_{3}\right)_{3} \mathrm{C}-\mathrm{CH}\left(\mathrm{OH}_{2}\right)$ $\left.\mathrm{CH}_{3}\right]^{+}: \mathrm{PES}$ and IRC

A partial representation of the PES, C(2)-O bond distance and $\mathrm{C}(4)-\mathrm{C}(3)-\mathrm{C}(2)$ bond angle, obtained with the AM1 method (AM1-PES) for the $\left[\left(\mathrm{CH}_{3}\right)_{3} \mathrm{C}-\mathrm{CH}\left(\mathrm{OH}_{2}\right)\right.$ $\left.\mathrm{CH}_{3}\right]^{+}$cation, is presented in Figure 2 with the IRC and the structures of the main stationary points. Indeed, this PES presents two transition states (TS1 and TS2) connecting the reactant and the intermediate complex, $\left[\left(\mathrm{CH}_{3}\right)_{3} \mathrm{C}\right.$ $\left.\mathrm{CHCH}_{3}\right]^{+\ldots \mathrm{OH}_{2}}$, and connecting this intermediate to the product complex, $\left[\left(\mathrm{CH}_{3}\right)_{2} \mathrm{C}-\mathrm{CH}\left(\mathrm{CH}_{3}\right)_{2}\right]^{+} \ldots \mathrm{OH}_{2}$. The main results for the stationary point in the AM1-PES are summarized in Table 1.

Table 1. Relative enthalpy and Gibbs energy $\left(\mathrm{kJ} \mathrm{mol}^{-1}\right)$ at $298 \mathrm{~K}$ for the stationary points in the AM1-PES

\begin{tabular}{lcc}
\hline Species & $\Delta \Delta \mathrm{H}$ & $\Delta \Delta \mathrm{G}$ \\
\hline Reactant, $\left[\left(\mathrm{CH}_{3}\right)_{3} \mathrm{C}-\mathrm{CH}\left(\mathrm{OH}_{2}\right) \mathrm{CH}_{3}\right]^{+}$ & 0 & 0 \\
TS1 & 26.4 & 23.0 \\
Intermediate complex, $\left[\left(\mathrm{CH}_{3}\right)_{3} \mathrm{C}-\mathrm{CHCH}_{3}\right]^{+} \ldots \mathrm{OH}_{2}$ & 24.0 & 13.6 \\
Dissociated intermediate, $\left[\left(\mathrm{CH}_{3}\right)_{3} \mathrm{C}-\mathrm{CHCH}_{3}\right]^{+}+\mathrm{H}_{2} \mathrm{O}$ & 72.6 & 20.2 \\
TS2 & 112.1 & 94.5 \\
Product complex, $\left[\left(\mathrm{CH}_{3}\right)_{2} \mathrm{C}-\mathrm{CH}\left(\mathrm{CH}_{3}\right)_{2}\right]^{+} \ldots \mathrm{OH}_{2}$ & -27.1 & -44.0 \\
Dissociated product, $\left[\left(\mathrm{CH}_{3}\right)_{2} \mathrm{C}-\mathrm{CH}\left(\mathrm{CH}_{3}\right)_{2}\right]^{+}+\mathrm{H}_{2} \mathrm{O}$ & 13.7 & -36.2 \\
\hline
\end{tabular}

Using standard approximations for an ideal gas, entropic contributions have been obtained. They systematically stabilized all species and, as expected, the dissociated ones more significantly. Due to the nature of the cationwater complex of the intermediate and product species, there are many local minima with quasi-degeneracy. The two most important structures in each complex region are presented with the squares denoting structures obtained from the optimization of the last IRC point. In contrast, with the B3LYP/6-31G(d)-PES illustrated in Figure 3, which presented a concerted IRC, the dehydration of $\left[\left(\mathrm{CH}_{3}\right)_{3} \mathrm{C}-\mathrm{CH}\left(\mathrm{OH}_{2}\right) \mathrm{CH}_{3}\right]^{+}$went through an intermediate complex in the AM1-PES. The IRC in the AM1-PES ended 
at bonded cation-water complexes, which are quite stable (48.6 $\mathrm{kJ} \mathrm{mol}^{-1}$ for the intermediate and $40.8 \mathrm{~kJ} \mathrm{~mol}^{-1}$ for the product) compared to the dissociated species. Since the activation enthalpy associated with TS1 $\left(26.4 \mathrm{~kJ} \mathrm{~mol}^{-1}\right)$ is smaller than that of TS2 $\left(88.1 \mathrm{~kJ} \mathrm{~mol}^{-1}\right)$, it is expected that the intermediate would be formed faster than it would dissociate into products, so that it would accumulate during the reaction.
Protonated 3,3-dimethylbutan-2-ol, [( $\left.\mathrm{CH}_{3}\right)_{3} \mathrm{C}-\mathrm{CH}\left(\mathrm{OH}_{2}\right)$ $\mathrm{CH}_{3} \mathrm{~J}^{+}$: dynamics

The dynamics of $\left[\left(\mathrm{CH}_{3}\right)_{3} \mathrm{C}-\mathrm{CH}\left(\mathrm{OH}_{2}\right) \mathrm{CH}_{3}\right]^{+}$started from its equilibrium structure and the classical equipartition energy $\left(0.040 \mathrm{E}_{\mathrm{h}}=105 \mathrm{~kJ} \mathrm{~mol}^{-1}\right)$ was distributed by a random Maxwell-Boltzmann atomic velocity distribution and randomly through the normal modes. In addition, the

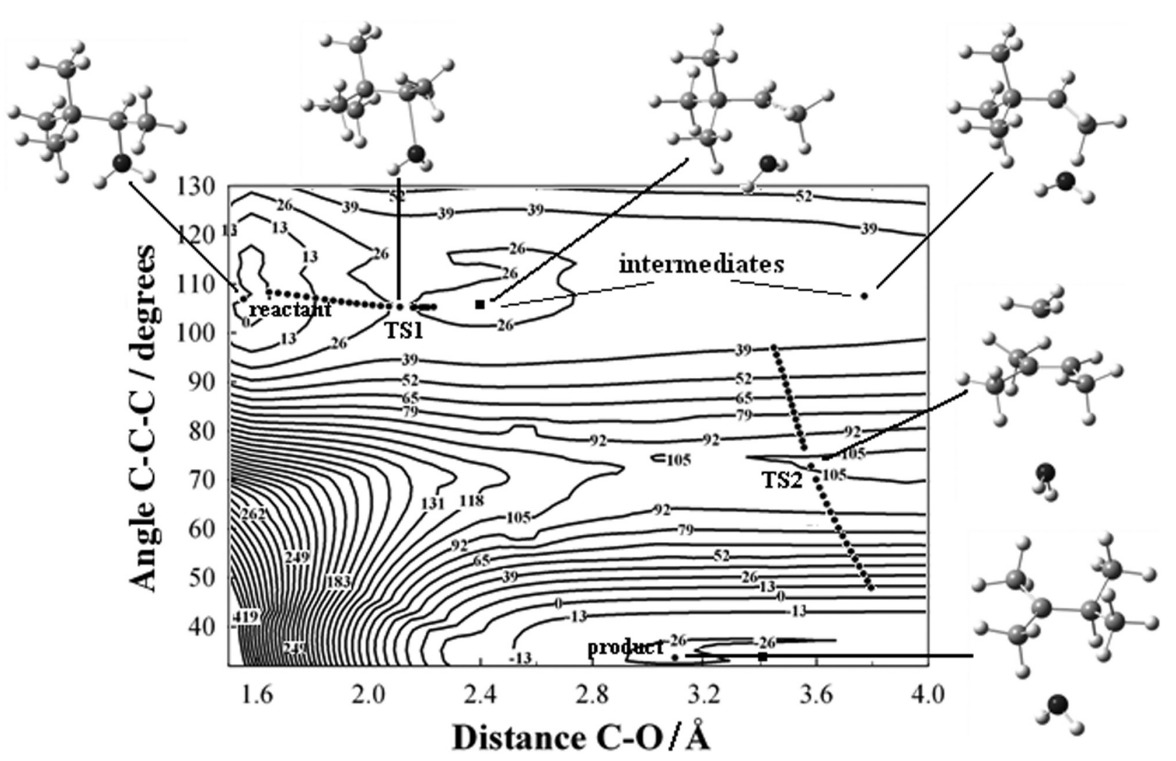

Figure 2. Potential energy contour map for protonated $(R)$-3,3-dimethylbutan-2-ol, $\left[\left(\mathrm{CH}_{3}\right)_{3} \mathrm{C}-\mathrm{CH}\left(\mathrm{OH}_{2}\right) \mathrm{CH}_{3}\right]^{+}$calculated with the AM1 method. The structures of the stationary points and the intrinsic reaction coordinates (IRC) are illustrated. The squares correspond to local minima obtained from the optimization of the last IRC point.

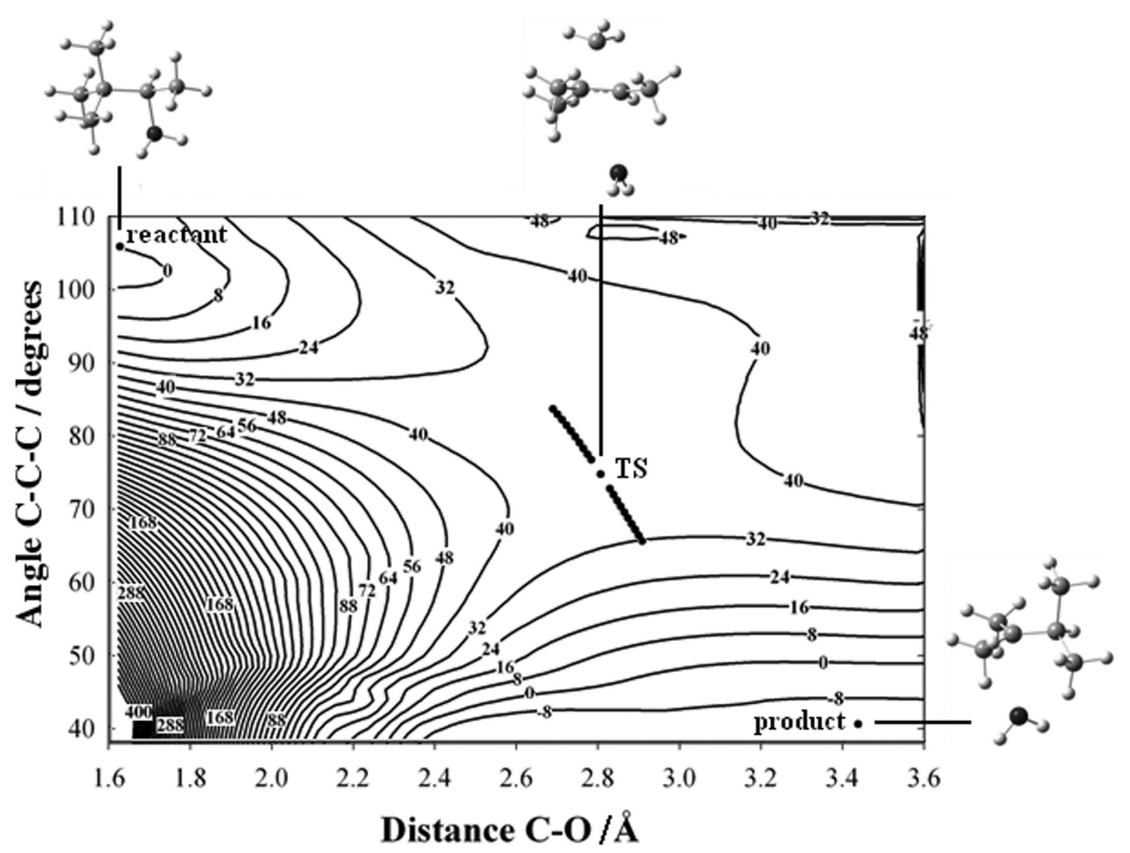

Figure 3. Potential energy contour map for protonated $(R)$-3,3-dimethylbutan-2-ol, $\left[\left(\mathrm{CH}_{3}\right)_{3} \mathrm{C}-\mathrm{CH}\left(\mathrm{OH}_{2}\right) \mathrm{CH}_{3}\right]^{+}$calculated with the B3LYP/6-31G(d) method. The structures of the stationary points and the intrinsic reaction coordinate (IRC) are illustrated. 
normal modes were perturbed by a simulated annealing (SA) type approach where a random amount of energy was given to a normal mode chosen from a distribution proportional to its vibrational frequency.

Using random velocities, the initial energy is distributed through so many incoherent degrees of freedom that all trajectories remain in the reactant region of the PES, despite the energy barrier through TS1 being four times smaller than the initial energy. These results are to be contrasted with the dynamics of the same system started from random velocities using the HF/6-31G* method at constant temperature for which almost $50 \%$ of the trajectories left the reactant region of the PES to end in the intermediate, despite the IRC being concerted. ${ }^{10}$

We have also chosen to distribute the equipartition energy amongst the first ten lowest vibrational modes due to the classical description of the nuclear motions. More specifically, it is known that the unrestricted energy flow between the classical motions is more pronounced for the higher vibrational frequencies modes. Thus, using this approach we hope that these high frequency motions will not affect the dynamics, so that some shortcomings of using classical trajectories can be minimized. Using this approach, $85 \%$ of the trajectories remained in the reactant region of the PES, $15 \%$ of the trajectories went over the barrier to yield the intermediate. Since the intermediate can be a water-cation complex or a cation and water fragment, a further analysis yielded less than $1.5 \%$ remaining in the complex and more than $13.5 \%$ of the trajectories yielded the dissociated system. Note that these latter trajectories are highly non-IRC despite the dissociated intermediate being almost $50 \mathrm{~kJ} \mathrm{~mol}^{-1}$ less stable than the bounded complex. These results are similar to the dynamics of the $\mathrm{OH}^{-}+\mathrm{CH}_{3} \mathrm{~F} \rightarrow \mathrm{CH}_{3} \mathrm{OH}+\mathrm{F}^{-} \mathrm{S}_{\mathrm{N}} 2$ reaction ${ }^{12}$ where the hydrogen-bonded complex $\mathrm{CH}_{3} \mathrm{OH} \cdots \mathrm{F}^{-}$ is avoided in almost all trajectories. In addition, the water fragment carries most of the initial energy as kinetic energy, so that the cation intermediate does not have enough energy to go through TS2 in order to yield the rearranged cation. A typical trajectory that ended at the dissociated intermediate is illustrated in Figure 4a.

Considering that during a typical trajectory the molecular system can collide with other species or with the container walls and thus would be perturbed, we performed simulated annealing-type direct dynamics to mimic these effects. Since this approach depends upon several variables, a large number of trajectories were calculated to account for their variations. According to the classification presented in Figure $1,82 \%$ of these trajectories ended in the intermediate region, $10 \%$ remained in the reactant, $5 \%$ went to the products via a concerted path, $3 \%$ followed other types
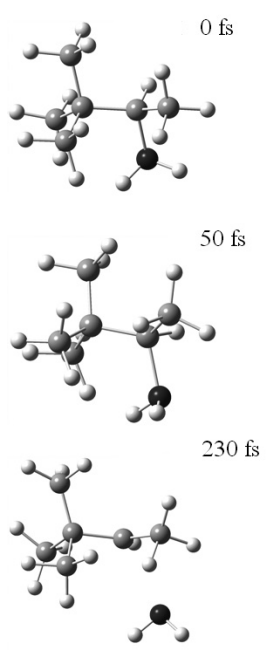

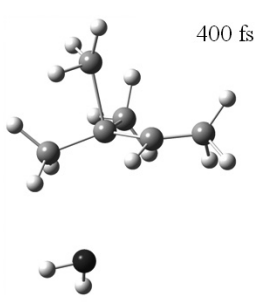

(a)
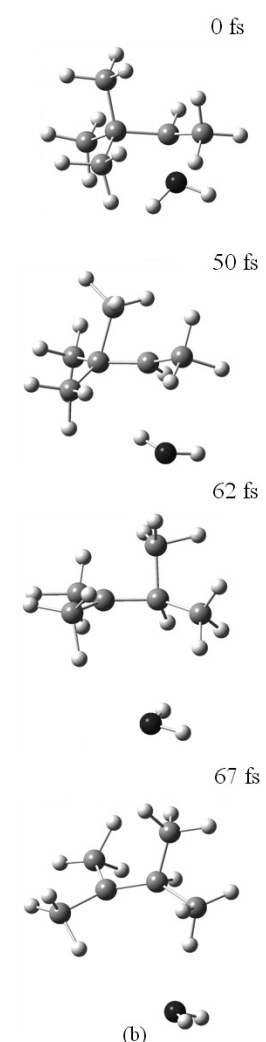

(b)
Figure 4. Structures of typical trajectories leading to (a) the non-rearranged dissociated product and (b) the concerted rearranged product.

of path, and only $0.5 \%$ ended in the product region via a stepwise path. This last result can be explained when we consider the nature of the trajectories that were classified as intermediate. Indeed, almost all of these trajectories (>97\%) ended at the dissociated $\left[\left(\mathrm{CH}_{3}\right)_{3} \mathrm{C}-\mathrm{CHCH}_{3}\right]^{+}$intermediate plus water. In addition, most of the initial and perturbation energies were distributed to the translational degrees of freedom of the water fragment, so that the energy remaining in the $\left[\left(\mathrm{CH}_{3}\right)_{3} \mathrm{C}-\mathrm{CHCH}_{3}\right]^{+}$intermediate is not enough to overcome the barrier associated with TS2, thus yielding a stepwise path. Illustrations of the structures involved in typical trajectories that ended at the intermediate and at the product via a concerted path are presented in Figures $4 \mathrm{a}$ and $4 \mathrm{~b}$, respectively. Note that despite the large amount of energy used to perturb the trajectories the structures are quite plausible and most of this energy is distributed amongst the internal rotation motions and angular deformations. In addition, a measurable amount of trajectories followed a concerted path (TS region in Figure 1), which is not predicted by a static analysis of the PES. This is the opposite analog of the direct dynamics with the HF/6-31G(d) method that yields mostly non-concerted paths, despite the concerted path being the IRC.

In order to search for patterns or correlations between the results of the dynamics and the initial conditions, 
we performed a principal component analysis $(\mathrm{PCA})^{44}$ of the whole calculated data. Indeed, no pattern was found when the lowest four principal components were analyzed (Figure S-2 in the Supplementary Information) regarding the reaction paths or the vibrational modes. A possible explanation for this lack of patterns is the very fast intramolecular vibrational energy redistribution compared to the reaction dynamics.

\section{Ethene + 1,3-butadiene cycloaddition: PES and IRC}

The cycloaddition reaction between ethene and 1,3-butadiene is part of a set of pericyclic reactions for benchmarking of computational methods. ${ }^{45}$ The reason is that it has well established experimental data and there is some consensus that its transition state is symmetric with the reaction path being concerted. ${ }^{29}$ Indeed, the AM1-PES illustrated in Figure 5 is quite similar to other potential energy surfaces obtained by high level electronic structure methods. ${ }^{29}$ The IRC treatment predicts a concerted, synchronous, and symmetric reaction path.

The activation and reaction enthalpies are 99.4 and $-236.2 \mathrm{~kJ} \mathrm{~mol}^{-1}$, respectively, which compare adequately with the benchmark values: 101.2 and $-168.0 \mathrm{~kJ} \mathrm{~mol}^{-1}{ }^{45}$ In addition, the AM1 method yields relatively small energy values for deformation from the symmetric structure, which is consistent with some $a b$ initio and density functional theory calculations. ${ }^{46,47}$ Thus, the dynamics of this reaction using the AM1 method should provide at least qualitative results consistent with higher level electronic structure methods.

\section{Ethene + 1,3-butadiene cycloaddition: dynamics}

One of the main points concerning the reaction mechanism of cycloaddition is related to its concertedness and synchronicity, which have been debated for quite some time, ${ }^{48,49}$ and it now seems that, from an IRC treatment for symmetric dienes and dienophiles, the reaction path is concerted, synchronous, and symmetric. ${ }^{29}$ That is another reason for choosing this symmetric system, because the criterion for concertedness can be based only upon geometric information. In addition to the geometric criteria, the synchronicity of the reactions, especially Diels-Alder, has been quantified by differences of bond indexes using Boys localized molecular orbitals $s^{50}$ or Wiberg indices calculated with the natural bond orbital approach. ${ }^{51}$ However, when the reaction dynamics is considered, the correct criterion needs to address the nuclear motions relative to the time scale of the reaction coordinate. ${ }^{46}$ As a result, we have used the geometric criterion with various cutoffs (differences in the bond distances of the two forming bonds) and distances of the two forming bonds so that the dynamical effects on the reaction concertedness can be taken into account. Typical trajectories evolving in symmetric and asymmetric paths are illustrated in Figures 6a and 6b, respectively.

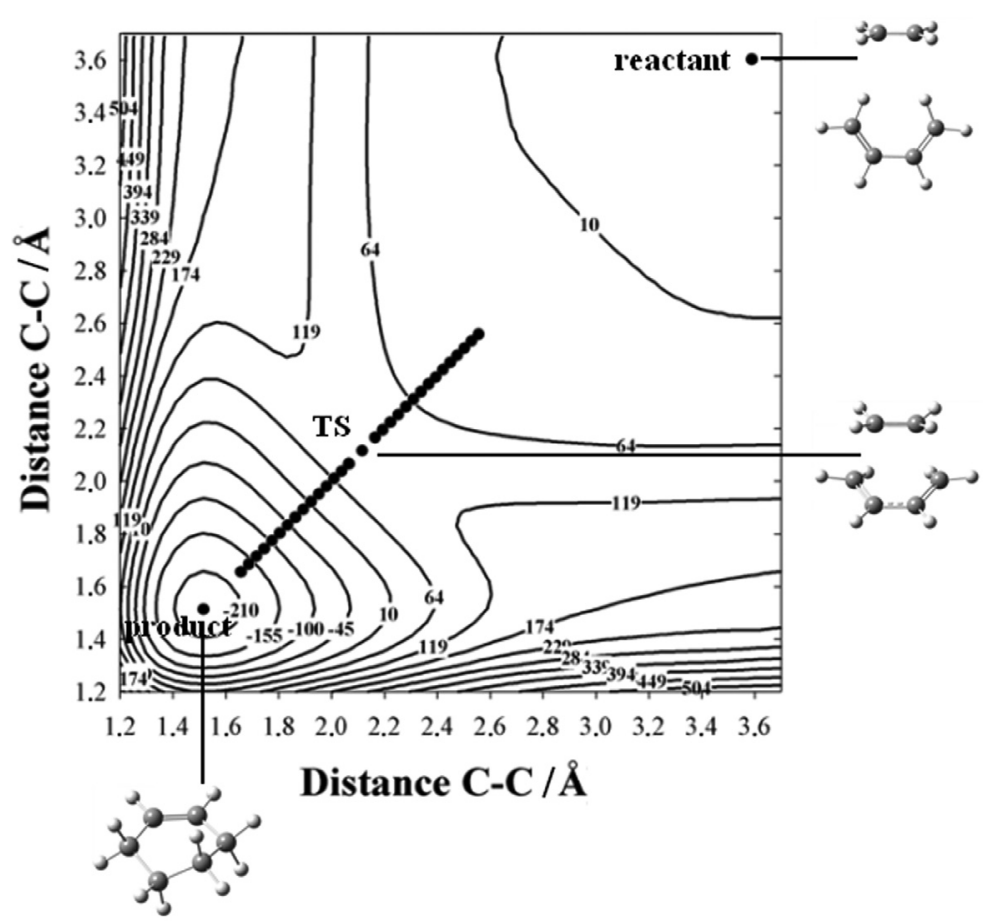

Figure 5. Potential energy contour map for ethene + 1,3-butadiene cycloaddition calculated with the AM1 method. The structures of the stationary points and the intrinsic reaction coordinate (IRC) are illustrated. 

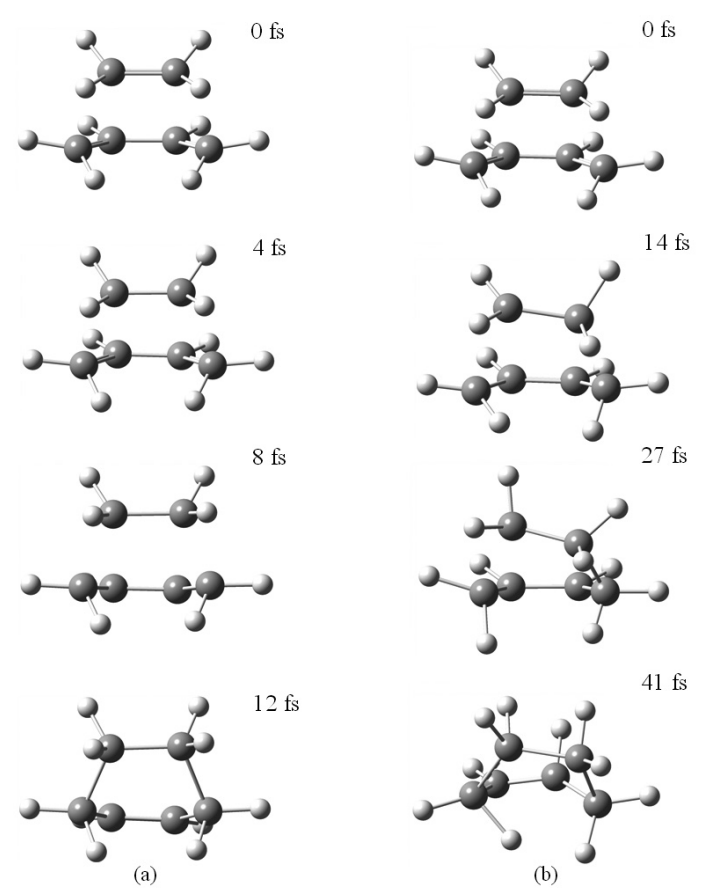

Figure 6. Structures of typical trajectories leading to product through (a) symmetric and (b) asymmetric paths.

Similar to protonated pinacolyl alcohol, the dynamics of the ethene $+1,3$-butadiene cycloaddition TS has been performed with the random velocities, random modes, and SA/F approaches. For the random velocities initialization, $75 \%$ of the trajectories went to the product and approximately $25 \%$ of the trajectories ended at the product through an asymmetric path, considering a difference of 0.1 A between the two forming bonds. A more detailed analysis is presented in Figure 7.

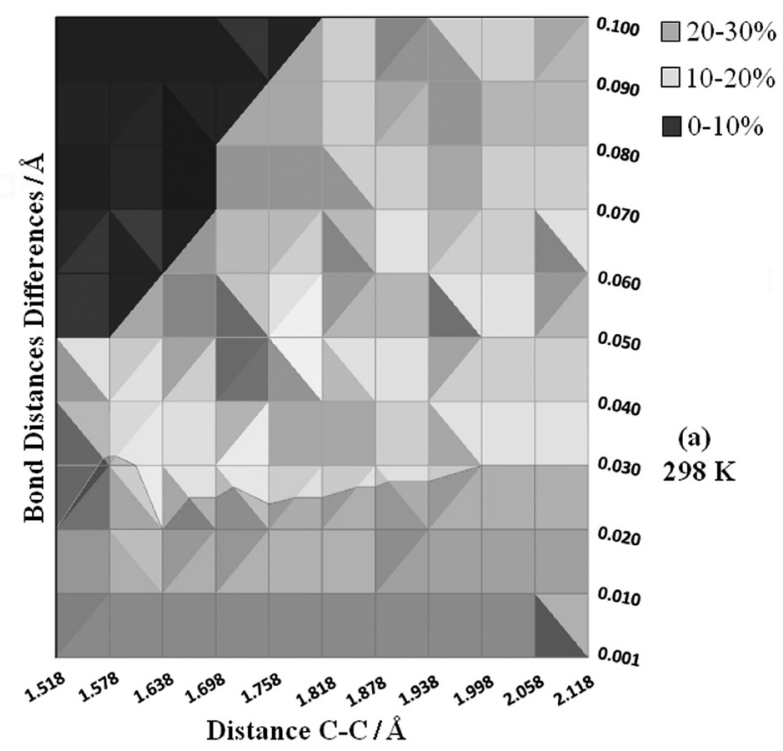

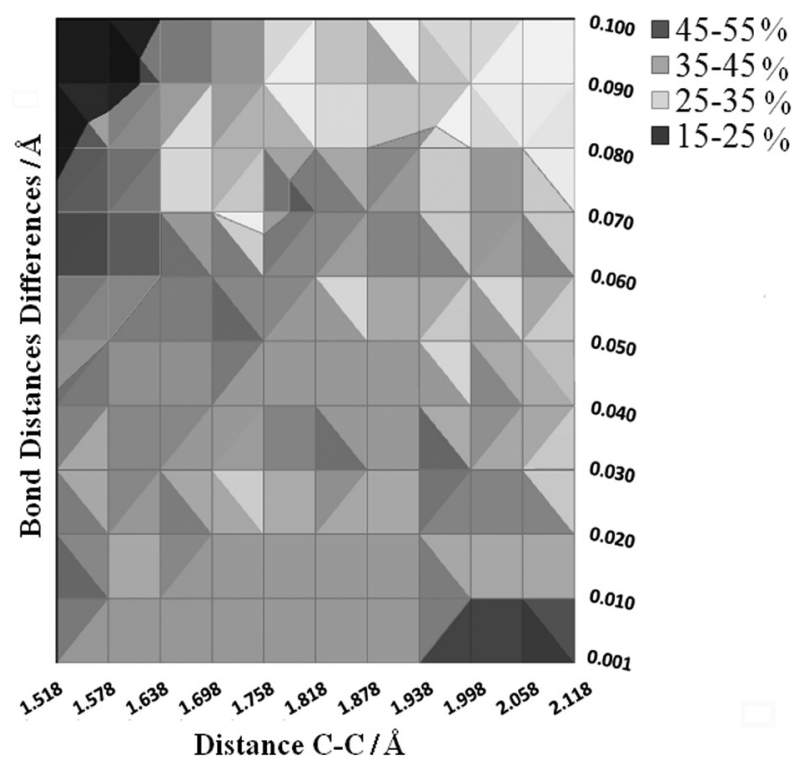

Figure 7. Percentage of trajectories from the TS (distance $\mathrm{C}-\mathrm{C}=2.12 \AA$ ) leading to the product (distance $\mathrm{C}-\mathrm{C}=1.52 \AA$ ) via an asymmetric path as a function of the asymmetry measured by the difference between the distances of the two forming bonds. The dynamics used random velocities initialization consistent with a distribution at $400 \mathrm{~K}$.

These can be contrasted to the results obtained for the initial energy distributed randomly amongst the 10 lowest vibrational modes for which only $15 \%$ of the trajectories ended at product. Thus, we increased to 20 the number vibrational modes included in this random energy distribution, which increased to $35 \%$ the number of trajectories that ended at product. Nearly $20 \%$ of the trajectories went through an asymmetric path to the product at $400 \mathrm{~K}$ (Figure 8a). When the simulation temperature

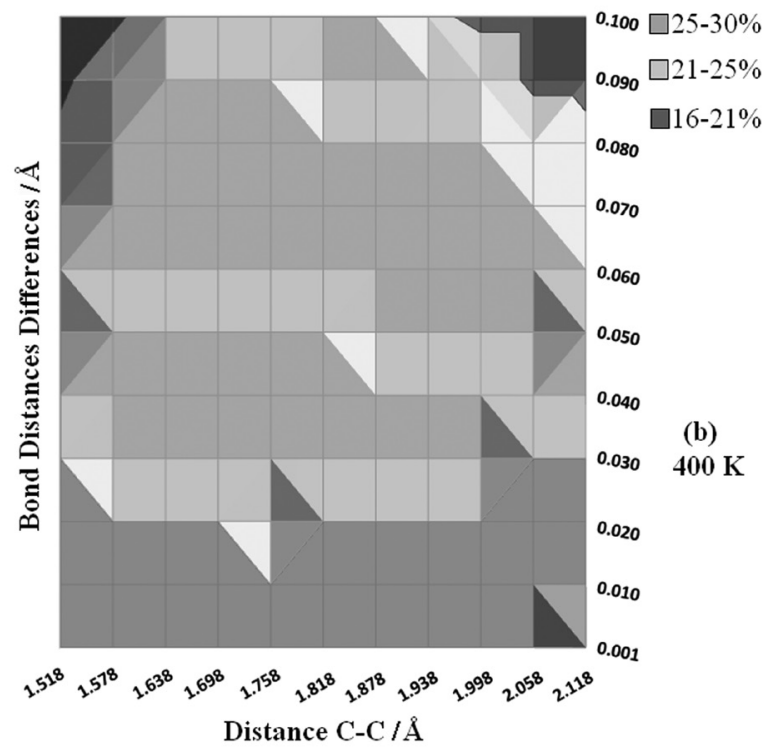

Figure 8. Percentage of trajectories from the TS (distance $C-C=2.12 \AA$ ) leading to the product (distance $C-C=1.52 \AA$ ) via an asymmetric path as a function of the asymmetry measured by the difference between the distances of the two forming bonds. The dynamics started with the initial kinetic energy at (a) $298 \mathrm{~K}$ and (b) $400 \mathrm{~K}$ randomly distributed to the 20 lowest frequency vibrational modes. 

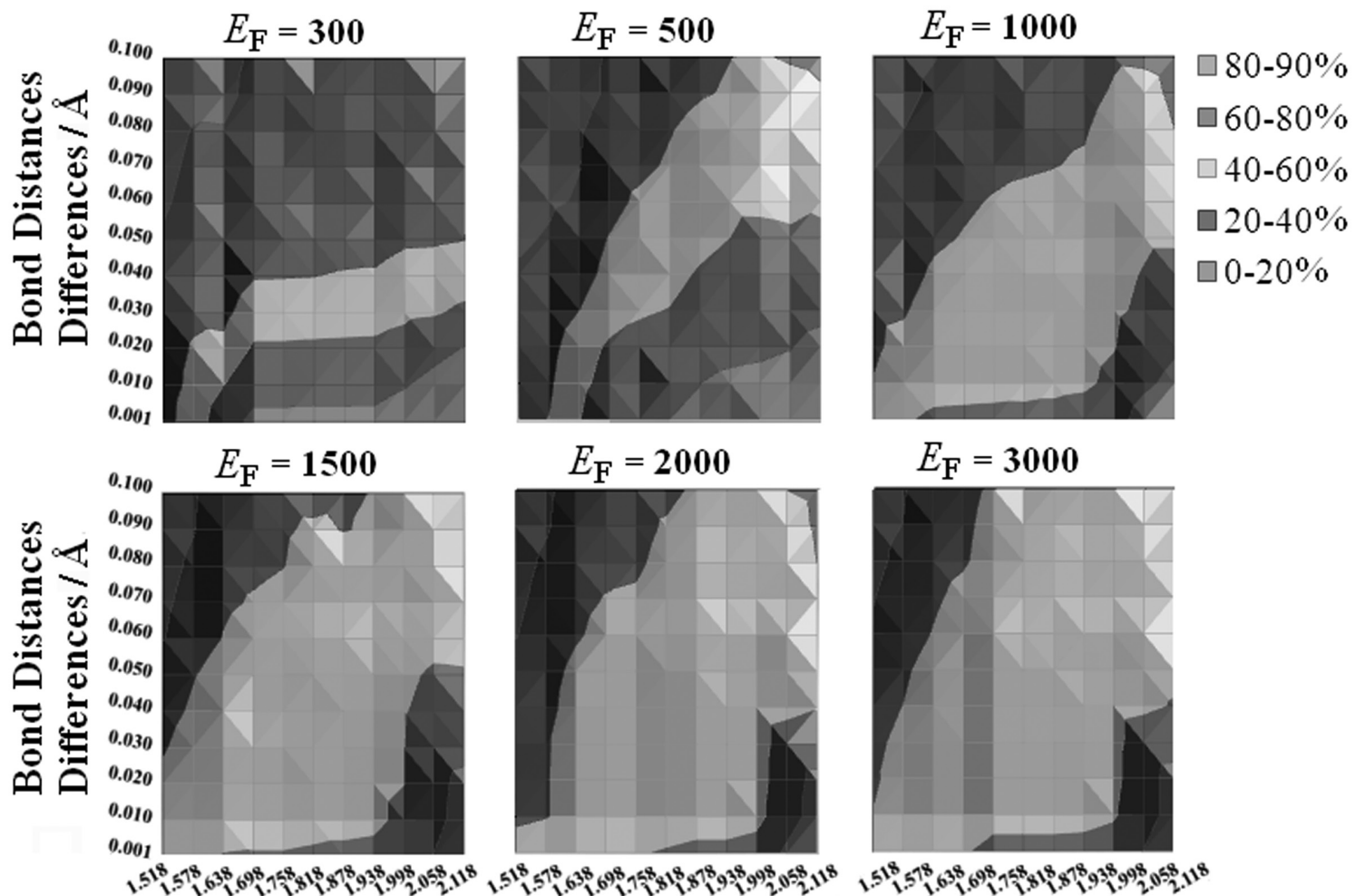

Distance $\mathrm{C}-\mathrm{C} / \AA \quad$ Distance $\mathrm{C}-\mathrm{C} / \AA \quad$ Distance $\mathrm{C}-\mathrm{C} / \AA$

Figure 9. Percentage of trajectories from the TS (distance $\mathrm{C}-\mathrm{C}=2.12 \AA$ ) leading to the product (distance $\mathrm{C}-\mathrm{C}=1.52 \AA$ ) via an asymmetric path as a function of the asymmetry measured by the difference between the distances of the two forming bonds. The dynamics was perturbed by the simulated annealing/ fragmentation approach that depends upon the Fermi energy $\left(\mathrm{E}_{\mathrm{F}}\right)$, which select the normal modes that will be enhanced or reduced.

was decreased to $298 \mathrm{~K}$, nearly $50 \%$ of the trajectories ended at the product and $10 \%$ through asymmetric paths, as depicted in Figure 8b.

A more detailed analysis was performed for the SA/F approach since it depended upon several parameters. The most relevant is the Fermi energy $\left(E_{F}\right)$ that selects the modes to be enhanced or reduced. The dependence of the reaction synchronicity upon the Fermi energy is presented in Figure 9.

Clearly, when low energy vibrational modes $\left(\mathrm{E}_{\mathrm{F}}<1000 \mathrm{~cm}^{-1}\right)$ are enhanced, the number of trajectories evolved in non-IRC (asymmetric) paths is smaller than when larger values of $\mathrm{E}_{\mathrm{F}}\left(>1500 \mathrm{~cm}^{-1}\right)$ are used. However, even when a small number of vibrational modes are enhanced $\left(\mathrm{E}_{\mathrm{F}}<300 \mathrm{~cm}^{-1}\right)$, the number of asymmetric trajectories is significant (20 to 40\%), showing that, independent of the initialization approach, this reaction shows some degree of asynchronicity, which is consistent with femtosecond dynamics. ${ }^{46}$ It should be noted that in many trajectories of SA/F, the enhanced mode corresponds to the internal rotation of the $\mathrm{C}-\mathrm{C}$ bond, which would lead to a gaucheout diradical type intermediate ${ }^{46}$ that would be responsible for a non-concerted pathway. Indeed, these pathways were not observed in the calculated trajectories, which is also consistent with femtosecond dynamics. ${ }^{46}$ Additional studies are underway to establish if the absence of non-concerted pathways is due to the dynamics of the internal rotation compared to the dynamics of the bond formation, or due to the lack of flexibility of the restricted Hartree-Fock AM1 type wavefunction.

\section{Conclusions}

The AM1 direct dynamics of protonated pinacolyl alcohol, $\left[\left(\mathrm{CH}_{3}\right)_{3} \mathrm{C}-\mathrm{CH}\left(\mathrm{OH}_{2}\right) \mathrm{CH}_{3}\right]^{+}$, and of the ethene $+1,3$-butadiene cycloaddition yields many non-IRC (intrinsic reaction coordinate) trajectories. For the first system, the IRC path ends at the $\left[\left(\mathrm{CH}_{3}\right)_{3} \mathrm{C}-\mathrm{CHCH}_{3}\right]^{+\ldots} \mathrm{OH}_{2}$ intermediate complex, however, most trajectories ended at the dissociated secondary carbocation, $\left[\left(\mathrm{CH}_{3}\right)_{3} \mathrm{C}\right.$ $\left.\mathrm{CHCH}_{3}\right]^{+}$, and the water fragment. The water molecule carries most of the initial energy, so that the secondary carbocation, $\left[\left(\mathrm{CH}_{3}\right)_{3} \mathrm{C}-\mathrm{CHCH}_{3}\right]^{+}$, does not yield the rearranged tertiary carbocation $\left[\left(\mathrm{CH}_{3}\right)_{2} \mathrm{C}-\mathrm{CH}\left(\mathrm{CH}_{3}\right)_{2}\right]^{+}$, nor the rearranged $\left[\left(\mathrm{CH}_{3}\right)_{2} \mathrm{C}-\mathrm{CH}\left(\mathrm{CH}_{3}\right)_{2}\right]^{+} \ldots \mathrm{OH}_{2}$ product complex, which is the ending point of the IRC. In addition to these non-IRC trajectories, the concerted pathway has been found in the direct dynamics calculations 
using the simulated annealing/fragmentation approach. Unlike the IRC on the potential energy surfaces (PES) calculated by the RHF/6-31G and B3LYP/6-31G(d) methods that correspond to the concerted reaction path (water dissociation and $\mathrm{CH}_{3}$ migration), this path is not observed in the AM1-PES, but some trajectories went through this highly non-IRC pathway. Regarding the dynamics starting from the symmetric Diels-Alder TS (transition state) of ethene $+1,3$-butadiene, a significant amount of trajectories followed asymmetric pathways, which are also non-IRC. These results are quite independent of the approach used to initialize the dynamics or on the perturbations used during dynamics. It should be noted that all trajectories yielded the concerted product. Studies are underway to investigate the origin of the concertedness and to explore the nonsynchronicity of some trajectories, so that the dynamical relations between concertedness, synchronicity and the symmetric path can be established.

\section{Acknowledgments}

The Brazilian Agencies CAPES, CNPq, CT-Petro, FINEP, and RENAMI are acknowledged for partial financial support as well as for graduate scholarships and research fellowship for the authors.

\section{Supplementary Information}

Supplementary data and AVI files for the movies of typical trajectories for the dynamics of the protonated pinacolyl alcohol (alcohol_1.avi through alcohol_6.avi) and the Diels-Alder reaction (DA_1.avi through DA_4.avi) are available free of charge at http://jbcs.sbq.org.br as PDF file.

\section{References}

1. Payne, M. C.; Teter, M. P.; Allan, D. C.; Arias, T. A.; Joannopoulos, J. D.; Rev. Mod. Phys. 1992, 64, 1045.

2. Deumens, E.; Diz, A.; Longo, R.; Öhrn, N. Y.; Rev. Mod. Phys. 1994, 66, 917.

3. Bolton, K.; Hase, W. L.; Peslherbe, G. H. In Modern Methods for Multidimensional Dynamics Computation in Chemistry; Thompson, D. L., ed.; World Scientific: Singapore, 1998, pp. 143-189.

4. Ben-Nun, M.; Martínez, T. J.; Adv. Chem. Phys. 2002, 121, 439.

5. López, J. G.; Vayner, G.; Lourderaj, U.; Addepalli, S. V.; Kato, S.; deJong, W. A.; Windus, T. L.; Hase, W. L.; J. Am. Chem. Soc. 2007, 129, 9976.
6. Dong, E. J.; Setser, D. W.; Hase, W. L.; Song, K.; J. Phys. Chem. A 2006, 110, 1484.

7. Li, J.; Shaik, S.; Schlegel, H. B.; J. Phys. Chem. A 2006, 110, 2801.

8. Li, J.; Li, X.; Shaik, S.; Schlegel, H. B.; J. Phys. Chem. A 2004, $108,8526$.

9. Yamataka, H.; Aida, M.; Dupuis, M.; J. Phys. Org. Chem. 2003, $16,475$.

10. Ammal, S. C.; Yamataka, H.; Aida, M.; Dupuis, M.; Science 2003, 299, 1555.

11. Yamataka, H.; Aida, M.; Dupuis, M.; Chem. Phys. Lett. 2002, 353,310 .

12. Sun, L.; Song, K.; Hase, W. L.; Science 2002, 296, 875.

13. Fukui K.; J. Phys. Chem. 1970, 74, 4161.

14. Anslyn, E. V.; Dougherty, D. A.; Modern Physical Organic Chemistry, University Science Books: Sausalito, CA; 2006, p. 374.

15. Carpenter, B. K.; Annu. Rev. Phys. Chem. 2005, 56, 57.

16. Lowry, T. H.; Richardson, K. S.; Mechanism and Theory in Organic Chemistry, $3^{\text {rd }}$ ed., Harper \& Row: New York, 1987, p. 1090.

17. Shaik, S.; Danovich, D.; Sastry, G. N.; Ayala, P. Y.; Schlegel, H. B.; J. Am. Chem. Soc. 1997, 119, 9237.

18. Bakken, V.; Danovich, D.; Shaik, S.; Schlegel, H. B.; J. Am. Chem. Soc. 2001, 123, 130.

19. Bertran, J.; Gallardo, I.; Moreno, M.; Saveant, J. M.; J. Am. Chem. Soc. 1996, 118, 5737.

20. Yamataka, H.; Aida, M.; Dupuis, M.; Chem. Phys. Lett. 1999, 300, 583.

21. Deumens, E.; Diz, A.; Taylor, H.; Öhrn, Y.; J. Chem. Phys. 1992, 96, 6820 .

22. Longo, R.; Diz, A.; Deumens, E.; Öhrn, N. Y.; Chem. Phys. Lett. 1994, 220, 305.

23. Peslherbe, G. H.; Hase, W. L.; J. Chem. Phys. 1994, 100, 1179.

24. Stock, G.; Müller, U.; J. Chem. Phys. 1999, 111, 65.

25. Kirkpatrick, S.; Gelatt, Jr., C. D.; Vecchi, M. P.; Science 1983, 220,671 .

26. Trost, B. M.; Miller, M. L.; J. Am. Chem. Soc. 1988, 110, 3687.

27. Diau, E. W.-G.; De Feyter, S.; Zewail, A. H.; Chem. Phys. Lett. 1999, 304, 134.

28. Houk, K. N.; Gonzales, J.; Li, Y.; Acc. Chem. Res. 1995, $28,81$.

29. Houk, K. N.; Beno, B. R.; Nendel, M.; Black, K.; Yoo, H. Y.; Wilsey, S.; Lee, J. K.; THEOCHEM 1997, 398-399, 169.

30. Dewar, M. J. S.; Pierini, A. B.; J. Am. Chem. Soc. 1984, 106, 203.

31. Dewar, M. J. S.; Jie, C.; Acc. Chem. Res. 1992, 25, 537.

32. Firestone, R. A.; Tetrahedron 1996, 52, 14459.

33. Kraka, E.; Wu, A; Cremer, D.; J. Phys. Chem. A 2003, 107, 9008. 
34. Karadakov, P. B.; Cooper, D. L.; Gerratt, J.; J. Am. Chem. Soc. 1998, 120, 3975.

35. Wilsey, S.; Houk, K. N.; Zewail, A. H.; J. Am. Chem. Soc. 1999, 121, 5772 .

36. Horn, B. A.; Herek, J. L.; Zewail, A. H.; J. Am. Chem. Soc. 1996, 118,8755 .

37. Frisch, M. J.; Trucks, G. W.; Schlegel, H. B.; Scuseria, G. E.; Robb, M. A.; Cheeseman, J. R.; Montgomery, J. A.; Vreven, T.; Kudin, K. N.; Burant, J. C.; Millam, J. M.; Iyengar, S.; Tomasi, J.; Barone, V.; Mennucci, B.; Cossi, M.; Scalmani, G.; Rega, N.; Petersson, G. A.; Nakatsuji, H.; Hada, M.; Ehara, M.; Toyota, K.; Fukuda, R.; Hasegawa, J.; Ishida, M.; Nakajima, T.; Honda, Y.; Kitao, O.; Nakai, H.; Klene, M.; Li, X.; Knox, J. E.; Hratchian, H. P.; Cross, J. B.; Adamo, C.; Jaramillo, J.; Gomperts, R.; Stratmann, R. E.; Yazyev, O.; Austin, A. J.; Cammi, R.; Pomelli, C.; Ochterski, J.; Ayala, P. Y.; Morokuma, K.; Voth, G. A.; Salvador, P.; Dannenberg, J. J.; Zakrzewski, V. G.; Dapprich, S.; Daniels, A. D.; Strain, M. C.; Farkas; Malick, D. K.; Rabuck, A. D.; Raghavachari, K.; Foresman, J. B.; Ortiz, J. V.; Cui, Q.; Baboul, A. G.; Clifford, S.; Cioslowski, J.; Stefanov, B. B.; Liu, G.; Liashenko, A.; Piskorz, P.; Komaromi, I.; Martin, R. L.; Fox, D. J.; Keith, T.; Al-Laham, M. A.; Peng, C. Y.; Nanayakkara, A.; Challacombe, M.; Gill, P. M. W.; Johnson, B.; Chen, W.; Wong, M. W.; Andres, J. L.; Gonzalez, C.; Replogle, E. S.; Pople, J. A.; Gaussian 03, revision D.02.

38. Dewar, M. J. S.; Zoebisch, E. G.; Healy, E. F.; Stewart, J. J. P.; J. Am. Chem. Soc. 1985, 107, 3902.

39. Millam, J. M.; Bakken, V.; Chen, W.; Hase, W. L.; Schlegel, H. B.; J. Chem. Phys. 1999, 111, 3800.
40. Lourderaj, U.; Song, K.; Windus, T. L., Zhuang Y.; Hase, W. L.; J. Chem. Phys. 2007, 126, 044105.

41. Hase, W. L. In Encyclopedia of Computational Chemistry; Schleyer, P. v. R.; Allinger, N. L.; Clark, T.; Gasteiger, J.; Kollman, P. A.; Scheafer, H. F.; III, Schreiner, P. R., eds., Wiley: Chichester, U. K., 1998, pp. 402-407.

42. Rocha, G. B.; Freire, R. O.; Simas, A. M.; Stewart, J. J. P.; J. Comput. Chem. 2006, 27, 1101.

43. Stewart J. J. P.; J. Mol. Model. 2007, 13, 1173.

44. Sharaf, M. A.; Illman, D. L.; Kowalski, B. R.; Chemometrics, Wiley: New York, 1986; Massart, D. L.; Vandeginste, B. G. M.; Deming, S. N.; Michotte, Y.; Kaufman, L.; Chemometrics: A Textbook; Elsevier: Amsterdam, 1988.

45. Guner, V.; Khuong, K. S.; Leach, A. G.; Lee, P. S.; Bartberger, M. D.; Houk K. N.; J. Phys. Chem. A 2003, 107, 11445.

46. Diau, E. W.-G.; De Feyter, S.; Zewail A. H.; Chem. Phys. Lett. 1999, 304, 134.

47. Wilsey, S.; Houk, K. N.; Zewail, A. H.; J. Am. Chem. Soc. 1999, 121,5772 .

48. Dewar, M. J. S.; J. Am. Chem. Soc. 1984, 106, 209.

49. Borden, W. T.; Loncharich, R. J.; Houk, K. N.; Annu. Rev. Phys. Chem. 1988, 39, 213.

50. Moyano, A.; Perichs, M. A.; Serratosa, F.; Valentí, E.; J. Org. Chem. 1987, 52, 5532.

51. Cossío, F. P.; Morao, I.; Jiao, H.; Schleyer, P. v. R.; J. Am. Chem. Soc. 1999, 121, 6737.

Received: November 17, 2008 Web Release Date: April 9, 2009 


\section{A Direct Dynamics Study of Protonated Alcohol Dehydration and the Diels-Alder Reaction}

Marcus V. P. dos Santos, Erico S. Teixeira and Ricardo L. Longo*

Departamento de Química Fundamental, Universidade Federal de Pernambuco, 50740-540 Recife-PE, Brazil

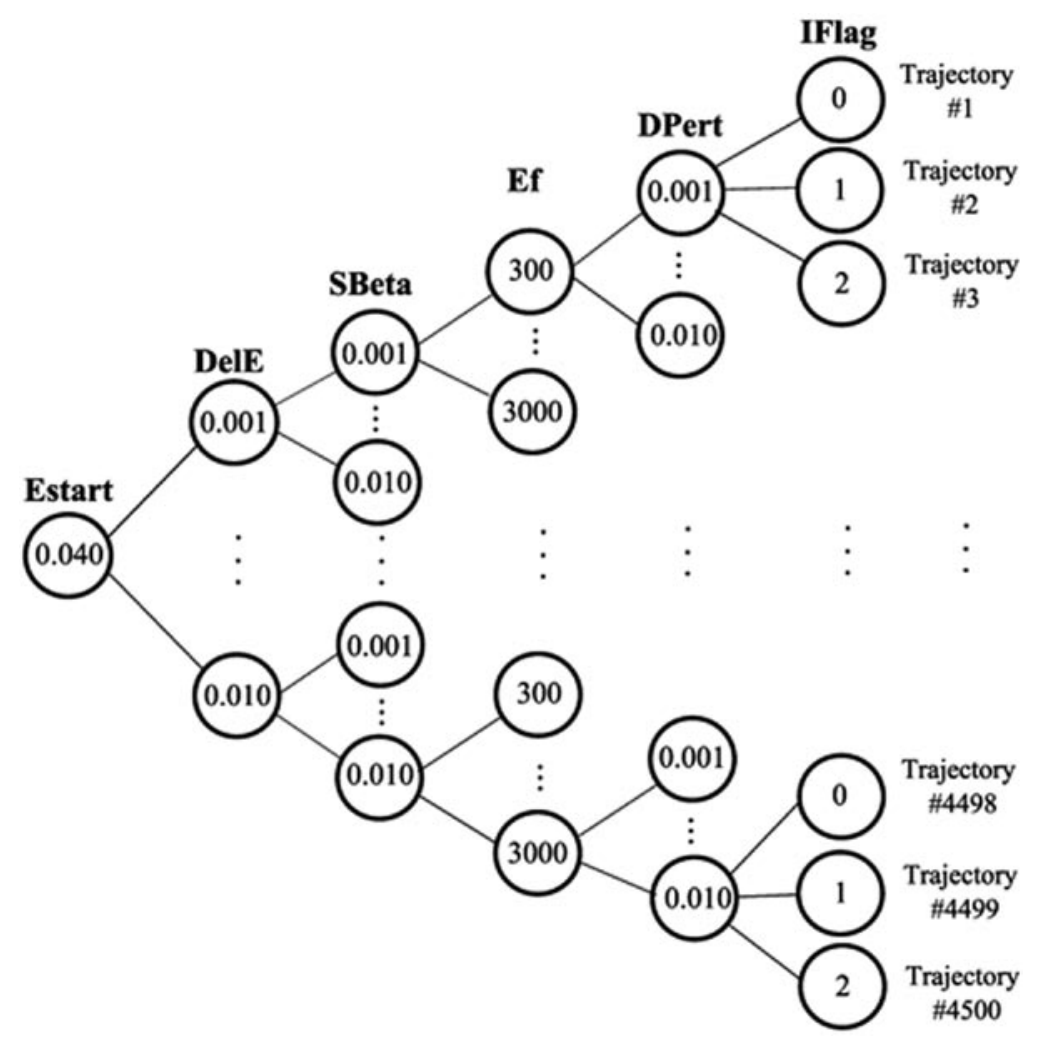

Figure S1. Flow-tree chart for generating the trajectories for the AS/F approach. 

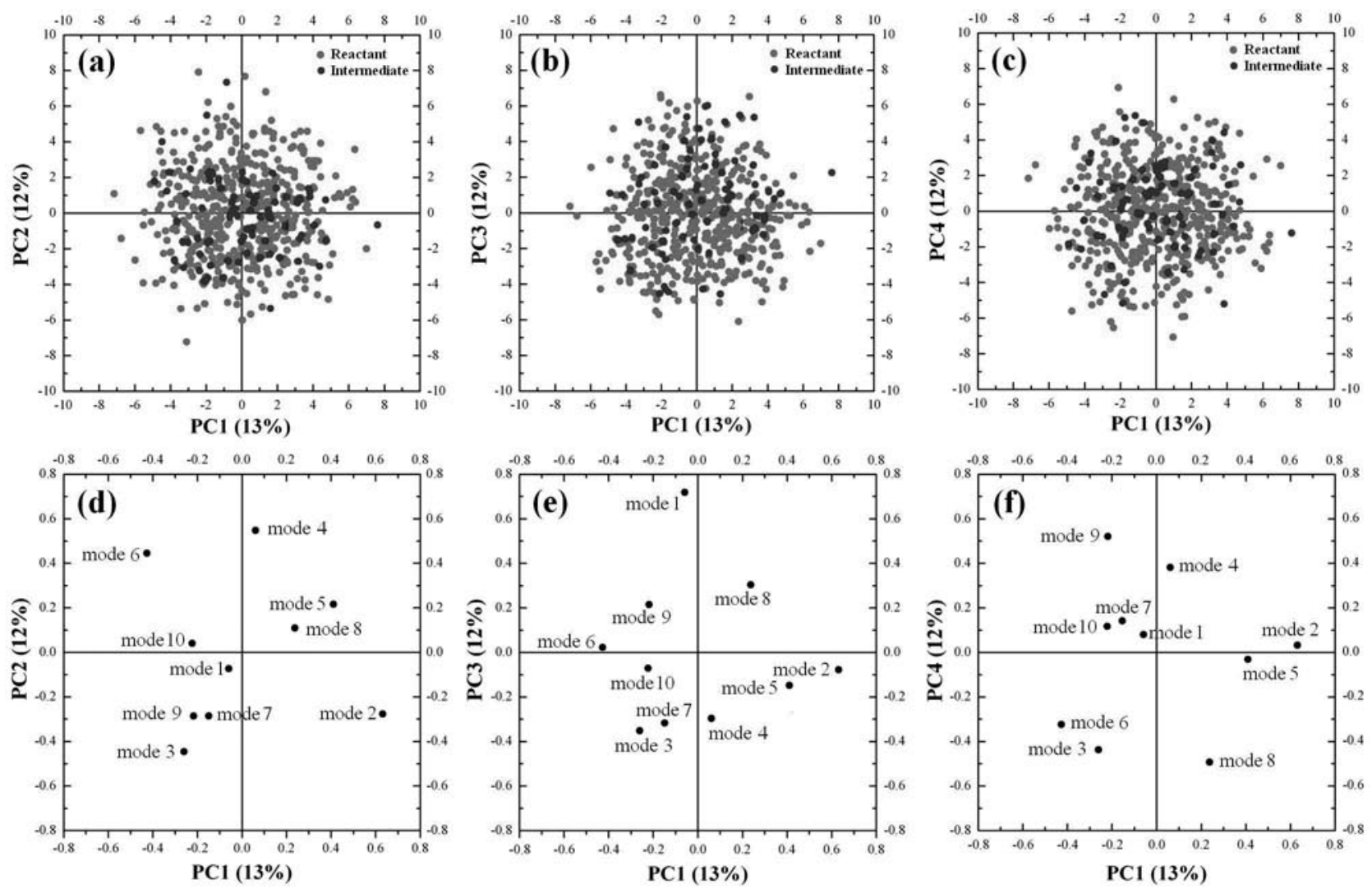

Figure S2. Principal component analysis of the reaction paths and vibrations modes for the dynamics of the protonated alcohol dehydration. 